\section{Differential effect of visual and auditory complexity on the EEG: Negative hedonic value as a crucial variable?*}

\author{
ANTHONY GALE†, PETER BRAMLEY, BONNIE LUCAS \\ and BRUCE CHRISTIE \\ University of Exeter, Exeter, Devon, England
}

Four experiments are reported. In Experiment 1, EEG abundance is shown to decrease as complexity of visual stimuli increases. Stimuli are a blank screen or $2,4,8$, or 16 black dots randomly placed on a white background. This result is in accordance with previous findings and is consonant with arousal theory. However, in Experiment 2, EEG abundance is shown to increase with auditory complexity. Stimuli are 30-sec blocks of 1,2,3, or 4 tones randomly alternated. In Experiment 3, Ss rate the sound stimuli for both complexity and hedonic value. Ratings for complexity and hedonic value run counter to each other, Ss rating less complex stimulj as ugly, irritating, and unpleasant. Thus the contradictory results of Experiments 1 and 2 are explicable in terms of the negative hedonic value of simpler, more monotonous stimuli, the arousing effects of which may override any effects induced by complexity per se. In Experiment 4, Ss give hedonic ratings for stimuli used in both Experiments 1 and 2. The findings for Experiment 3 are replicated. An irritating-relaxing scale differentiates between the visual and auditory stimuli.

Several studies have demonstrated a relationship between complexity of visual stimulation and abundance of the EEG. Following predictions derived from arousal theory (e.g., Berlyne, 1960), alpha abundance is found to decrease as complexity increases (Berlyne \& McDonnell, 1965; Baker \& Franken, 1967; Gale, Dunkin, \& Coles, 1969; Gale, Christie, \& Penfold, 1971; Gale, Coles, \& Boyd, 1971 Christie, Delafield, Lucas, Winwood, \& Gale, in press). All these studies have employed occipital EEG as a dependent variable. The question arises as to whether the results are attributable entirely to activity in the visual projection cortex and/or peripheral effects (such as mechanical adjustments of the eyes) or if it is necessary to postulate a more general mechanism (e.g., arousal or activation). Gale et al (1971) showed that alpha activity varied linearly with $\log _{2}$, the number of elements in a visual display $(2,4,8,16$, or 32 random white squares on a black background), i.e., alpha abundance decreased with increasing complexity. Experiment 1 in the present study extends these results to displays of black circles on a white background (see Fig. 1). In addition, an intermediate presentation time ( $30 \mathrm{sec})$ is used: previous studies have used either briefer presentations (e.g., Berlyne \& McDonnell, 1965) or longer presentations (e.g., Gale et al, 1971). Gale et al (1971) included separate

*This work was supported by a grant from the Medical Research Council to the senior author (No. G969/185/C)

tAnthony Gale is now at University College of Swansea, Wales, U.K. stimulus sets to measure brightness effects (white squares of varying size placed centrally on a black background). In the present study, such lowest complexity level). a control is not necessary, since the total area of white decreases as complexity increases (see Fig. 1). Thus, if brightness per se is a source of alpha attenuation, one would predict increasing alpha with increasing complexity. The control for brightness is therefore built into the slides. A further modification of the previous experiment is the inclusion of a blank screen condition (minimum complexity, maximum brightness). Thus, Experiment 1 is an extension of the study by Gale et al (1971). In Experiment 2, this conception of visual complexity is translated into the auditory mode. Tones are presented at a rate of $1 / 1 / 2$ sec. Four different tones are used, and single tones, pairs, triplets, and quadruplets are presented in random sequences for $1 / 2-\min$ trials. The prediction is that high-complexity conditions (i.e., quadruplets) would be most arousing and would therefore be associated with the lowest-amplitude EEG. The outcome is, in fact, significantly contrary to this prediction, more complex stimuli being associated with significantly greater alpha abundance. In Experiment 3, therefore, two related hypotheses are tested: (1) that the tone patterns do vary subjectively in complexity in the

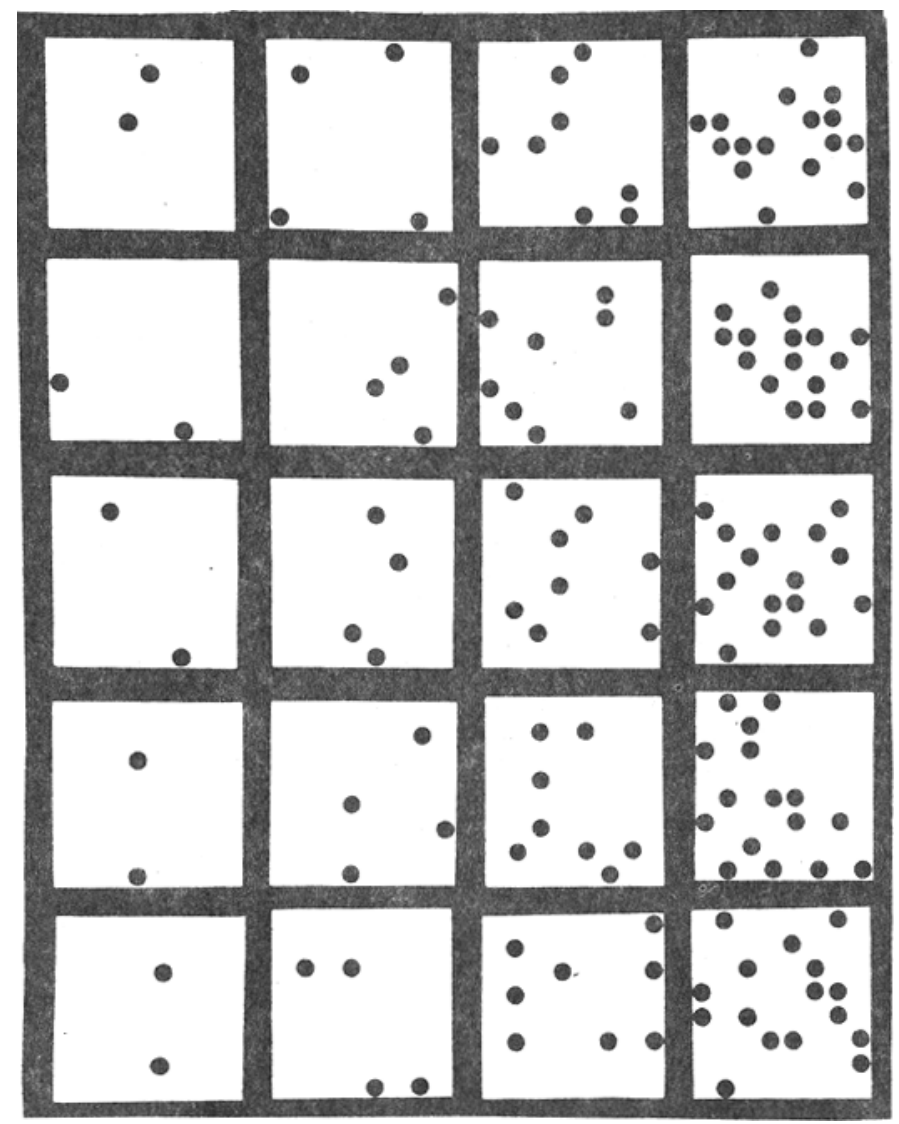

Fig. 1. Stimuli used in Experiment 1 (each set also included a blank, i.e., 

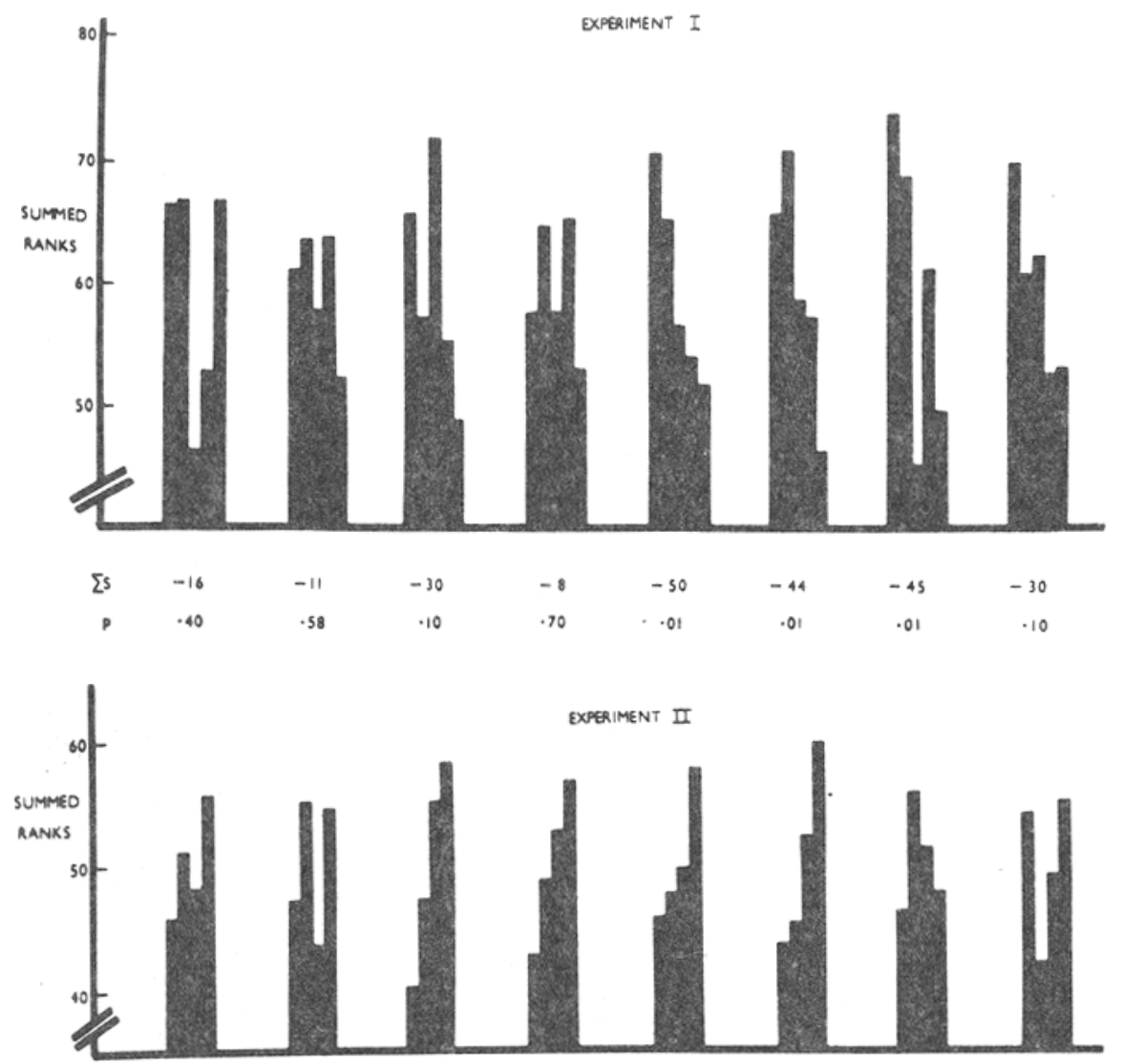

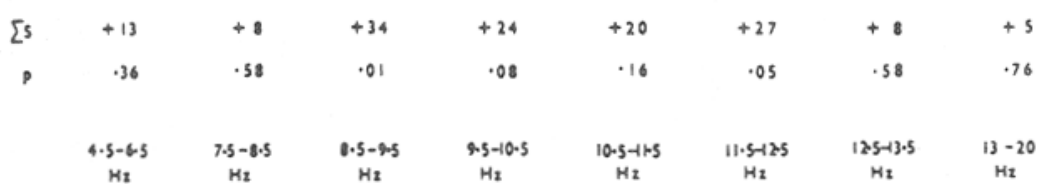

Fig. 2. Summed ranks of EEG abundance values for visual (Experiment 1) and auditory (Experiment 2) stimuli, showing sign of trend and associated probability value for each frequency measured. Complexity increases moving left to right across the figure (i.e., top graph, blank first; bottom graph, single tone first).

expected direction, but (2) the simpler tone patterns are more annoying or irritating. If this is the case, it could be argued that the increase in alpha activity with increasing auditory complexity is a result of a decrease in the distress-induced arousal produced by monotonous repetition of a single tone and not a result of auditory complexity per se. Experiment 4 replicates Experiment 3 but adds ratings for the visual patterns used in Experiment 1, as well as the tone patterns used in Experiment 2.

\section{EXPERIMENT 1}

\section{Subjects}

The Ss were 11 undergraduate students and 9 soldiers (average age, 20 years 7 months).

The EEG

Silver/silver chloride pad electrodes
An identical procedure applied to Experiment 2.

\section{The Stimuli}

The stimuli are shown in Fig. 1. A blank screen condition (minimum complexity) was also used. The dots in the stimuli were placed at random in an $8 \times 8$ matrix and photographed onto slides. The schedule of presentation was identical for all Ss. Each row in Fig. 1 (with the addition of a blank) was presented in order, randomizing within each row. Each slide was presented for $30 \mathrm{sec}$, with an interslide interval of $5 \mathrm{sec}$. There were thus 25 trials, with a total testing time of approximately $15 \mathrm{~min}$. Prior to the experiment, the brightness of the projector was adjusted to ensure that any postpresentation afterimage would decay within 5 sec.

\section{Procedure}

The $S$ sat in an adjustable chair in a soundproofed cubicle, $7 \mathrm{ft}$ from the screen, with his line of regard at right angles to the center of the screen. In spite of soundproofing, the $S$ could hear the constant and regular beat of the tape punch in the adjacent experimental room. The room was dark, apart from the illumination provided by the projector. The $\mathbf{S}$ was instructed to attend to the slides, to keep them in focus, and to avoid counting the dots.

\section{Results}

A 25-sec sample was extracted for each trial (omitting the first 5 -sec epoch, which may have obtained samples relating to the previous trial). Samples for each complexity level were summed, and the EEG values for the levels were ranked for each $\mathrm{S}$. The order of ranks was tested with a monotonic trend test (Ferguson, 1965) for each filter taken separately. The ranks (summed over the $20 \mathrm{Ss}$ ) and the corresponding probability values are displayed in Fig. 2 (increasing complexity: left to right). Also displayed in Fig. 2 are the values of $\Sigma S$, from which the probability values were obtained. The sign of $\Sigma S$ indicates the direction of the trend, being positive when the trend is an increasing one and negative when the trend is decreasing. It is clear from Fig. 2 that, although $\Sigma S$ is not always significant, the trend is a decreasing one for every filter.

\section{EXPERIMENT 2} Subjects

The Ss were 11 undergraduates and 9 soldiers (average age, 19 years 6 months). None of these Ss had taken part in Experiment 1.

The Stimuli

Four tones were used $(440,300$, 277 , and $220 \mathrm{~Hz}$ ). These form the chord of $A$ major. Intensity varied between $62 \mathrm{~dB}$ for the highest tone and $58 \mathrm{~dB}$ for the lowest. There were 
$48 \quad 30$-sec trials, each trial containing 60 tones presented at the constant rate of 1 per $500 \mathrm{msec}$. The duration of each tone was $250 \mathrm{msec}$. All possible selections of $1,2,3$, or 4 tones were used. Within each trial, the tones were presented in blocks of $1,2,3$, or 4 , depending on the complexity level. The blocks were not separated but, rather, formed a continuous sequence. The order of tones within a block was random. Thus, no tone was ever presented more than twice in succession (except in the single-tone condition). Trials were in sets of 12 . Within sets, identical conditions were never adjacent. For example, Set 1 was: $1,4,2,3,4,1,2,3,4,3,2,1$. This particular arrangement of the tone stimuli constitutes an attempt to translate the visual stimuli used in Experiment 1 into the auditory mode. Apart from the intuitive notion of an increase in complexity from the single tone to quadruplet conditions, we are able in addition to classify the tone conditions more rigorously in terms of uncertainty qua information theory, since events occur sequentially and are interdependent. Thus, in a quadruplet condition, where all tones appear randomly in each four-tone block, there is progressive reduction in uncertainty (i.e., which tone comes next?) within each block. In the single-tone condition, uncertainty is zero. Over any 30-sec trial, total uncertainty $(\mathrm{H})$ is approximately one tone, $\mathrm{H}=0$ bits; two tones, $\mathrm{H}=30$ bits; three tones, $\mathrm{H}=52$ bits; four tones, $H=68$ bits. Both the stimuli and the instructions were prerecorded on magnetic tape and played back to the Ss. Total testing time was $26 \mathrm{~min}$ (including a 2-min rest period after 24 trials ). ${ }^{1}$

Procedure

The Ss sat as in Experiment 1, with eyes open, viewing a colored slide of thorn trees in the sunset. The stimulus sequence was presented through a loudspeaker. The eyes-open condition was employed to reduce the possibility of drowsiness. To minimize effects of adjustments to the peripheral visual apparatus, the Ss were instructed to attend continuously to the slide presented.

\section{Results}

The results are displayed in Fig. 2.

Table 1

Mean Subjective Ratings for the Auditory Stimuli (Experiment 3)

\begin{tabular}{|c|c|c|c|c|c|c|}
\hline \multirow{2}{*}{$\begin{array}{c}\text { Low End } \\
\text { of Scale } \\
\text { (1) }\end{array}$} & \multicolumn{2}{|c|}{ Complexity } & \multicolumn{2}{|c|}{ Level Sounds } & \multirow{2}{*}{$\begin{array}{c}\text { High End } \\
\text { of Scale } \\
\text { (7) }\end{array}$} & \multirow[b]{2}{*}{$\mathbf{p}<$} \\
\hline & 1 & 2 & 3 & 4 & & \\
\hline Simple & 1.5 & $\mathbf{3 . 5}$ & 4.0 & 3.7 & Complex & .01 \\
\hline Boring & 1.8 & 3.4 & 4.2 & 4.8 & Interesting & .01 \\
\hline Ugly & 2.7 & 3.6 & 4.0 & 4.5 & Beautiful & .01 \\
\hline Irritating & 2.2 & 3.9 & 4.4 & 5.0 & Relaxing & .01 \\
\hline Unpleasant & 2.0 & 4.0 & 4.6 & 5.1 & Pleasant & .01 \\
\hline
\end{tabular}

Whereas the trends in Experiment 1 were all negative (i.e., decreasing), in this experiment, they are without exception positive (i.e., increasing). As in Experiment 1, not all the trends are statistically significant.

\section{EXPERIMENT 3}

Since some time elapsed before the results of Experiments 1 and 2 were analyzed, it was not possible to employ the same Ss for Experiment 3. Subjects

The Ss were 16 undergraduate students (average age, 21 years 6 months).

The Stimuli and Procedure

One 30-sec sample of each level of Experiment 2 was group-administered to the Ss. After each of the four trials, the Ss rated the stimulus sequence on five 7-point scales (simple-complex, boring-interesting, ugly-beautiful, irritating-relaxing, unpleasant-pleasant). The direction of the scales was varied to mitigate against the effects of response set.

\section{Results}

Still's (1967) nonparametric trend test was employed to test for linear trend components. The ratings (means for the $16 \mathrm{Ss}$ ) for each level of complexity and the probability values for the linear trend components are shown in Table 1. The multiple-tone conditions were judged to be significantly more complex than the conditions with few tones. However, they were also judged to be significantly more interesting, beautiful, relaxing, and pleasant.

\section{EXPERIMENT 4} Subjects

The Ss were 16 undergraduates (average age, 19 years), none of whom had participated in Experiments 1-3.

The Stimuli and Procedure

Twelve 30 -sec sound sequences and 12 dot patterns (exposed for $30 \mathrm{sec}$ each) were selected randomly from those used in Experiments 1 and 2 to give three examples of each level of auditory complexity and three of each level of visual complexity (excluding the blank screen condition). Ss observed visual patterns first and then the sounds; eight $S s$ observed in reverse order. After administration of the first sets, the $S s$ rated each stimulus on each of the five 7-point scales for the remaining two sets. Results

The results are presented (as for Experiment 3 ) in Table 2. DISCUSSION

The results of Experiments 1 and 2 run in opposite directions, the results for Experiment 2 being directly contrary to our predictions. The prediction for Experiment 2 would be supported by the work of Sharpless $\&$ Jasper (1956) on habituation to tone stimuli. Complex tone patterns should be slower to habituate and should therefore show greater alpha desynchronization than simpler tone patterns. Berlyne's (1960) hypothesis that complex stimuli contain more uncertainty and are more arousing than simple stimuli would also support this prediction. On the other hand, some industrial studies on the effects of noise on skilled performance (Broadbent, 1957) suggest that irritation (rather than perceived complexity perse) may be an important variable leading to disruption of skilled performance. The results of Experiment 2 suggest that it may also affect the EEG. The results of Experiments 3 and 4 support this view. The $S s$ rated the simpler tone conditions as more irritating than the more complex conditions. The design for Experiment 3 was limited. Only one sample per complexity level was administered, and no ratings were obtained of the slides used in Experiment 1 . However,

Table 2

Mean Subjective Ratings for Auditory and Visual Stimuli (Experiment 4)

\begin{tabular}{|c|c|c|c|c|c|c|c|c|c|c|c|}
\hline \multirow{2}{*}{$\begin{array}{l}\text { Low End } \\
\text { of Scale } \\
\text { (1) }\end{array}$} & \multicolumn{4}{|c|}{ Complexity Level Sounds } & \multirow[b]{2}{*}{$\mathbf{p}<$} & \multicolumn{4}{|c|}{$\begin{array}{l}\text { Complexity Level Patterns } \\
\text { (No Blank) }\end{array}$} & \multirow[b]{2}{*}{$\mathbf{p}<$} & \multirow{2}{*}{$\begin{array}{c}\text { High End } \\
\text { of Scale } \\
(7)\end{array}$} \\
\hline & 1 & 2 & 3 & 4 & & 1 & 2 & 3 & 4 & & \\
\hline Simple & 1.3 & 3.6 & 4.3 & 5.0 & .01 & 1.7 & 2.6 & 4.0 & 6.1 & .01 & Complex \\
\hline Boring & 1.5 & 3.6 & 4.5 & 5.3 & .01 & 2.6 & 3.7 & 4.4 & 5.8 & .01 & Interesting \\
\hline Ugly & 2.7 & 3.4 & 3.8 & 4.1 & .01 & 3.5 & 3.7 & 3.8 & 4.5 & .01 & Beautiful \\
\hline Irritating & 2.0 & 3.5 & 4.1 & 4.1 & .01 & 4.1 & 3.8 & 4.0 & 3.9 & n.s. & Relaxing \\
\hline Unpleasant & 1.9 & 3.4 & 4.3 & 4.6 & .01 & 3.9 & 3.9 & 4.3 & 5.0 & .01 & Pleasant \\
\hline
\end{tabular}


Experiment 4, employing a more satisfactory design, corroborates the findings for Experiment 3 and also those of Christie et al (in press) for similar visual patterns. Although neither experiment contains the original $S s$ used in the EEG experiments (for the reason given above), the replication of the findings for the sound stimuli strengthens the inference that similar effects applied to the Ss in Experiment 2. Both the visual and the auditory stimuli used in the present study varied in perceived complexity, interestingness, beauty, and pleasantness, but only the auditory stimuli varied in irritatingness.

There are, of course, other possible sources of EEG differences for Experiments 1 and 2, since it cannot be argued that the two experiments merely involve a translation of modality. Identical conditions for the two modalities are difficult, if not impossible, to achieve. There is variation in procedure in the two experiments, and a variety component intrudes in Experiment 2 . Nevertheless, the data presented in Table 2 indicates that perceived irritatingness could be the crucial variable. We must conclude that ratings of both complexity and hedonic value should be obtained prior to studies of the effects of stimulus arrays on the EEG.

The EEG findings for Experiment 1 support our earlier work. With this type of stimulus array, EEG abundance is a function of complexity. The high rankings for the blank slide confirm that brightness per se is not a relevant consideration. For the reasons given in the introduction, this inference may also be drawn from the findings for the patterned slides.

The finding that occipital EEG can be varied systematically (whatever the cause) by auditory stimuli provides sound support for the existence of a central mechanism and runs counter to the view that alpha variation is largely a by-product of eye mechanics (Lippold, 1970). Berlyne et al (1967) obtained results for auditory stimuli briefly presented (but in the direction predicted rather than obtained in Experiment 2). Further evidence for the effects of auditory stimuli on the EEG comes from a study by Gale, Haslum, \& Lucas (in press) in which they demonstrate systematic variation of EEG abundance to auditory verbal stimuli ranked for their alerting properties.

The experimental paradigms employed in the present study might well provide a sound basis for electrophysiological studies of individual differences in aesthetic preference, stress tolerance, and stimulus hunger (see Gale, 1969).

\section{REFERENCES}

BAKER, G., \& FRANKEN, R. Effects of stimulus size, brightness and complexity upon EEG desynchronization. Psychonomic Science, 1967, 7, 289-290.

BERLYNE, D. E. Conflict, arousal and curiosity. New York: McGraw-Hill, 1960. BERLYNE, D. E., \& MCDONNELL, P. Effects of stimulus complexity and incongruity on duration of EEG de sy n c hronization. Electroencephalography \& Clinical Neurophysiology, 1965 , $18,156-161$

BERLYNE, D. E., MCDONNELL, P. M.. NICKI, P. M., \& PARHAM, L. C. C. Effects of auditory pitch and complexity on EEG desynchronisation and on verbally expressed judgements. Canadian Journal of Psychology, 1967, 21, 346-367.

BROADBENT, D. E. Effects of noise on behaviour. In C. M. Harris (Ed.) Handbook of noise control New York: McGraw-Hill, 1957.

CHRISTIE, B., DEL AFIELD, G., LUCAS B., WINWOÖD, M., \& GALE, A. Stimulus complexity and the EEG: Differential effects of the number and variety of display elements. Canadian Journal of Psychology, in press.

FERGUSON, G. A. Nonparametric trend analysis: $A$ practical guide for research workers. Montreal: McGill University Press, 1965.

GALE, A. "Stimulus hunger": Individual differences in operant strategy in a button-pressing task. Behaviour Research \& Therapy, 1969, 7, 265-274.

GALE, A., CHRISTIE, B., \& PENFOLD, V. Stimulus complexity and the occipital EEG. British Journal of Psychology, $1971,62,527-531$.

GALE, A., COLES, M., \& BOYD, E. Variation in visual input and the occipital EEG: II. Psy chonomic Science, 1971, 23, 99-100.

GALE, A., DUNKIN, N., \& COLES, M. Variation in visual in put and the occipital EEG. Psychonomic Science, 1969, 14, 262-263.

GALE, A., HASLUM, M., \& LUCAS, B. Arousal value of the stimulus and EEG abundance in an auditory vigilance task. British Journal of Psy chology, in press.

LIPPOLD, $O$. Origin of the alpha rhythm. Nature, 1970, 226, 616-618.

SHARPLESS, S., \& JASPER, H. H. Habituation of the arousal reaction. Brain, 1956, 79, 655-680.

STILL, A. W. Use of orthogonal polynomials with nonparametric tests. Psychological Bulletin, 1967,68, 327-329.

\section{NOTE}

1. H was calculated in the following manner: Taking the four-tone condition, there are 15 quadruplet presentations per trial (60 tones in all). The first tone of each quadruplet has four possibilities (i.e., 2 bits), the second tone three ( 1.5 bits), the third tone two $(1 \mathrm{bit})$, and the fourth tone is determined ( 0 bits). Each of these events occurs 15 times; thus, multiplying uncertainty for each by 15 yields total uncertainty of $30+22.5+15+0=$ 67.5 bits. $H$ for the other conditions was calculated in a similar manner. 